\title{
Implementation of the ICT Program in Schools from the Point of View of the ICT Coordinators
}

\author{
Egoza Wasserman ${ }^{1} \&$ Chagit Refaeli ${ }^{2}$ \\ ${ }^{1}$ School of Education, Herzog Academic College, Jerusalem, Israel \\ ${ }^{2}$ ICT Coordinator, District Jerusalem, Israel \\ Correspondence: Egoza Wasserman, Herzog Academic College, Kampus Hiechal Shlomo, King Goerge street 57, \\ Jerusalem, 9107302, Israel. Tel: 972-2-532-0902.
}

Received: December 22, 2017

Accepted: January 18, 2018

Online Published: February 9, 2018

doi:10.20849/jed.v2i1.306

URL: https://doi.org/10.20849/jed.v2i1.306

\begin{abstract}
The purpose of this research is to examine the work of the ICT coordinator in the school: How does the coordinator see his role and work, what are the characteristics of the coordinators work and his relationship with supervisors, instructors, principals, teachers and students. The research was conducted in the qualitative method, the tool used to assemble data was a semi-structured interview; Ten ICT coordinators were interviewed from a variety of ages and a wide range of experience in teaching. The study found that ICT coordinators are the key figures in getting the process of implementation moving. The ICT coordinators know the importance of their roles in the schools and feel a great sense of responsibility. The coordinators are responsible for many fields, including the budgetary framework, promoting the teaching-learning process and leading school projects. The coordinators attest to a high level of trust with the principals and a good working relationship with the Ministry of Education's instructors, so that they have an open channel of dialogue and can consult with them. The work of the coordinator with the teachers consists of the pedagogical and technical aspect that are intertwined and attest to each other's existence.
\end{abstract}

Keywords: ICT coordinator, ICT leaders, teachers and technology

\section{Introduction}

Technological development affects every aspect of our lives and has not overlooked the field of education (Solomon, 2000). A crucial change that has been identified in the educational system in the past few years is the infiltration of innovative technology into the system and the implementation of ICT in the schools which have become an integral part of the teaching, learning and instructing process (Gaitanaru, 2014; Kozma, 2003; Halverson \& Smith, 2010; Selwyn, 2010). The Israeli educational system has come out with a program called "Adapting the educational system to the 21 st century". The goal of the program is to change the school into an online organization. The basic understanding of the program is that integrating technology into the educational system is not a goal in and of itself but rather a means to improve the quality of the educational system (teaching, learning, and evaluation) (Rimon, 2012). The main goals of the ICT program are: The transformation of schools into online organizations with advanced technology and assimilation of innovative pedagogy to impart 21 st century skills to students, with an emphasis on digital literacy. The Ministry of Education has a holistic concept which believes that in order to introduce ICT into the schools you have to start with the infrastructure and that infrastructure without maintenance has no value. Introducing digital content that is adapted to the learning program and developing the professionalism of the educations staff so that they will know how to utilize the advantages of the ICT. In addition, the operating budgets include ICT leaders, who are called school ICT coordinators.

\subsection{ICT Coordinator Leaders}

The ICT leaders work in the field of ICT and are at the cutting edge of the implementation of national ICT programs, and their role is becoming significant in the effective implementation of change in the schools (Vaillant, 2005; Ellis et al., 2016). These teachers are leading the technological pedagogic process and tend to adapt innovative tools that suit the needs of teaching and learning. These teachers see themselves as committed to the job and to the school, and they are willing to deal with changes in the organization and with the 
restructuring of programs. They testify that they have a vision for the system. The teacher that uses ICT has a profile of an empowered teacher with technological independence, pedagogical technological knowledge (Ungar \& Shamir-Inbal, 2016), based on experience in operating ICT technologies, and he conducts an intelligent combination of technology in the educational process (Mishra \& Koehler, 2006). The ICT leader experiences a change in his perception of his professional identity (Avidov-Ungar \& Shamir-Inbal, 2013); his knowledge expands and is updated throughout his career and he becomes an "adaptive expert" teacher (Darling-Hammond \& Bransford, 2005). In addition, ICT leaders are willing to invest a great deal for the sake of the school and to achieve its goals. The process of "empowerment is transformational" which occurs both on the individual level, by creating a professional identity of the teacher leading the pedagogic innovation, and also at the organizational level by implementing and managing projects and engaging in roles in the school system (Avidav-Ungar \& Illuz, 2013).

The role of ICT Coordinator was created in Israel in the late 90's along with the introduction of computers into the classroom where the main goal was to support the integration of computers on a technical level (Melamed, 2000). Tobin and Dayan (2007) in their study found that the role of ICT Coordinator, as it was described then was more of technician and less of a pedagogue. His importance was mainly at the first stage of computer operation in the school, and as time passes, the capability of the teachers increases and becomes as natural as reading and writing, the role of coordinator becomes less significant (Tobin \& Dayan, 2007).

Kleiman and Zamir (2008) identified three concepts that the coordinators express: a computer expert, a teacher and a computer instructor, a leader of change. The study found that a comprehensive change, which means assimilation of ICT in the learning programs and the organizational culture of the institution, can be initiated by the ICT coordinator who implements the three conceptions of the job together, in a way that complements each other (Schoenfeld \& Zelikowitz, 2010).

With the development of the process the role of the coordinator was defined anew: the school ICT coordinator will now control the entire field of ICT in the school. He is a teacher who initiates and leads a pedagogical transformation among the educational staff to instill a modernized perception that utilizes the advantages of computers and results from the national program "Adapting the Education System to the 21st Century". The coordinator must teach a field of knowledge at the school, and have proven experience in integrating ICT in teaching and familiarity with a variety of online tools, online learning environments and the educational catalog.

The school's ICT coordinator is responsible for implementing the ICT field in all the administrative, organizational and pedagogical aspects that are integrated into the teaching, learning and evaluation processes in the school. This is in line with the national program "Adapting the Education System to the 21st Century" (Ministry of Education, 2016). Implementation of the program is carried out in three main stages: a. the deployment stage, $b$. the procurement stage and $c$. the operational stage. The functions of the ICT coordinator vary in part from the deployment stage to the operating stage. His responsibilities include assimilating the Ministry of Education's ICT policy at the school, while maintaining consistent and ongoing contact with the district's ICT supervision and the Eshkol instructor. The following details the areas of responsibility of the ICT coordinator:

1) Building a curriculum for teaching computer and information literacy in the various fields of knowledge, subject to the policy of the program "Adapting the Education System to the 21st Century".

2) Responsibility for the planning, implementation and evaluation of a school program for teaching, learning and evaluation, combined with ICT requirements in the fields of education.

3) Introducing and implementing the various computer tools that are available to the school.

4) Professional development of the system's partners, assistance in professional development courses in the school in the field of ICT, subject to the program "Adapting the Education System to the 21st Century".

5) Safe internet surfing - Education of correct and balanced behavior while being protected on the Internet.

6) Collaborative learning and network communication.

7) The school portal - responsible for adapting the school portal for entrance to educational websites and learning environments.

In the ICT program the role of the ICT Coordinator is defined as an agent for change, a leader and adaptor of the school program's goals. They are responsible for implementing all parts of program along with personal development and concern for the development of the school's entire teaching staff. All of these lead to a review of the ICT coordinator's work and his perceptions of the characteristics of his work, his areas of responsibility, 
his vision, the challenges he faces and the labor relations that he maintains.

The purpose of this study is to examine the ICT coordinator's work in the school. The study examined the coordinator's perceptions in relation to the dream they bring with them to the work, their perceptions in relation to the characteristics of their work including their fields of responsibilities, the challenges they face and the working relationships they maintain.

\section{Methodology}

This study was conducted using the qualitative paradigm that provides an understanding of phenomena holistically by examining perceptions (Denzin \& Lincoln, 2011). The main tool selected for data collection is a semi-structured in-depth interview. Questions were asked regarding the coordinator's perceptions of his work, his work at school, and his connections with the financial sponsors, the school principal, teachers and students.

\subsection{The Participants and the Research Process}

The ten ICT coordinators interviewed included three men and seven women. The interviewees were a variety of ages from 4 to 28 years of experience in teaching. The interviews were conducted when it was convenient for the interviewees, and were arranged in advance, some in the school and some in other places, according to the interviewees' choice. Emphasis was placed on a relaxed atmosphere in order to gain the most out of the interview. The interviews lasted two hours and were recorded for further study.

\subsection{Data Analysis}

The analysis was based on identifying key themes and categories from the interviews. Encoding pages were developed in order to include quotations from interviewees according to themes and categories that were identified. The thematic analysis was carried out in several stages (Attride-Stirling, 2001; Braun \& Clarke, 2006) The first stage involved an in-depth knowledge of the raw data by reading the data several times and writing initial general ideas. The next stage involved building primary coding that represented significant characteristics that emerged from the text. In the third stage, the codes were grouped into categories, by collecting the data from the text, relevant to the proposed category. In the fourth stage, the categories were grouped into themes and a "theme map" was created. In the fifth stage, a repeat analysis was performed for each theme to observe how it related to the total data presented in the analysis.

\section{Results}

The role of the ICT coordinator contains the main categories: The perception of the coordinator, the characteristics of the coordinator's work and the working relationship of the coordinator with his co-workers. The categories will be presented below.

\subsection{The ICT Coordinator's Perception}

\subsubsection{The ICT Coordinator's Perception of His Role}

The ICT coordinators perceive their role as instructors who encourage the implementation of ICT in the schools to an extent that the implementation cannot take place without them, as R relates: A teacher who can take charge, is experienced and works for himself and the organization. It appears from his comment that choosing a coordinator requires a person who is willing to give of his time and effort for the good of the organization. The interviewee $\mathrm{M}$ thinks that the role of the coordinator is like a navigator. "I see him as one ... who creates and blows wind in the sails ... to cause the teachers and pupils to want more, and this means the wind must be strong enough to advance them but not too strong that it causes quitting or a feeling of being pushed too hard." From his words, it is possible to say that the coordinator's role is to navigate and lead together with the staff but at the same time to be attentive to their needs so as not to take control of the teachers. The interviewee $\mathrm{L}$ describes the need for a variety of skills, "You need the ability to take control, with some kind of technical talent, and to know how to talk to people like civil workers in the municipality or technicians and also to have good relations with the teachers". In her opinion, you need a variety of skills for the coordinator to succeed. Part of the necessary skills she adds is the need for unlimited enthusiasm and belief in your plan because this is what convinces people, "You need something that burns in you from within and you are always checking and testing ... helping the teachers and the principal to implement the program to make the program a reality and suitable to the school and teacher ..." According to her the role of the coordinator is to make the ICT program a reality. The interviewee $\mathrm{H}$ adds that it is important for the coordinator to be a significant figure in the fabric of the school, "Must be deeply involved in the school processes in order to influence ... the role took me into the inner workings of school management, I now understand better the thought process behind the decisions and the weight of people's character. I learned that success is dependent solely on me and my ability to persuade other people". 
From her remarks it can be concluded that because the coordinator is a central figure in the school, it is essential to his role to motivate the other people in the implementation of ICT. As can be seen from the statements of interviewee M., "because this is the task of the staff, everyone must want what you think is important". The coordinators perceive their jobs as being available to the teachers at all times. Thus interviewee R explains her role and that fulfilling this role is part of the job, "... in other words the ICT coordinator cannot walk down the hall without being stopped to answer questions ... this means that instructing is part of you wherever you go." Interviewee $\mathrm{L}$ adds to this that the job is without a framework and that successful fulfillment of the job is without limits in time and place, "the ICT coordinator is first and foremost a teacher that does not have special hours for the job he performs, the role is done incidentally, during study hours, break, etc. Therefore during breaks or study hours you circulate amongst the teachers and enquire and show interest and help when necessary ..." from this we see that the coordinator is aware of his double role as teacher and coordinator. And the coordinator's work is done throughout the day without special appointed hours. The findings indicate that the coordinators are fulfilling their mission with a vision and clear goals, yet they insist that the implementation should be done with the appropriate skills, such as patience and long term thinking, and the awareness that it is their enthusiasm that has inspired the process all the way.

\subsubsection{The Coordinator's Perception of ICT}

The coordinators come to their jobs with the clear perception that ICT in the school is not about the use of the computer but rather a combination of the possibilities inherent in the technological media and implementation of its tools in an intelligent manner. The interviewee $\mathrm{H}$ explains the use of the computer as a need, "A teacher opens the computer because he simply must. Opening the computer creates a learning process that goes beyond the boundaries of the classroom, really enlightening." In other words, the use of the computer is really an indispensable need. The interviewee M explains, "Oh, I think that the teacher who knows how to adapt ICT ... to the teaching itself, which is a subject that of course, he knows well enough to be able to use in a way that he can extract things from the web, that he knows how to conduct the lesson that it is not just an online lesson but a lesson of content that he wants, when he succeeds in using the online part in the right place. Of course there are other things like broad knowledge and high technical ability so he will not need external help every time." In other words, the main thing is the ability to utilize the computer for the good of the content. The interviewee A adds that the teacher that uses discretion in order to break the classic mode of the classroom attests to the correct application, "A teacher who exercises judgment, responds to challenges, breaks through the traditional classroom framework and traditional learning methods, encourages study and collaborative learning." In other words the teacher who uses discretion in his teaching and strives to improve the teaching-learning process by using these tools, will be successful in using them intelligently and in a significant manner. The interviewee $\mathrm{L}$ includes the factor of the pupil's connection, "the teacher who manages to do this thing, the learning, in ways that kids like more today, it's hard, it's hard to prepare like this all the time. That's what I think might be daunting, but it's worth it'. It is clear from his words that a teacher who manages to be meaningful manages to motivate the children to be involved and leads to meaningful learning. The interviewee $\mathrm{E}$ adds to this the importance of the teacher to be creative and initiative. "He builds units for individualized learning, and prepares students to be researchers and critics of knowledge." In her words, a teacher who independently produces the materials he uses successfully adapts himself to what is needed in the field and is relevant to his students and meaningful to them. In Interviewee L's opinion, the way is to engage the pupils in creating discussions and creating joint outcomes, "Creating collaborative discussions on the web and meaningful outcomes of meaningful learning. These projects involve a pupil or a group of pupils researching a specific field and then transmitting it in the plenum to everyone via electronic means." It can be understood from her words that the significant creativity is in the cooperation of the pupils in the contents and its products. The findings indicate that the best assimilation of ICT in schools, according to the coordinators, will take place when the teachers demonstrate independence in creating content, and use discretion to select the right tools for their needs, they will succeed in expanding the learning beyond the boundaries of the classroom and share with their pupil's both the choosing of content and building of the program and the creation of meaningful products.

\subsection{Specifications of the Coordinator's Job}

The work specifications of the Coordinator include areas of responsibility including the subject of coordinating, the challenges facing him and flexibility of time.

\subsubsection{The Coordinator's Field of Responsibility}

The responsibilities of the ICT coordinator are many and diffused over many areas, from the daily tasks of the ICT coordinators in the schools, to the responsibility for the technological equipment, the responsibility for 
training and more. From the comments of the coordinators one can say that they feel a great responsibility in their jobs. For example, Interviewee $\mathrm{H}$ explains that she feels like a bulldozer and super-responsible for advancing the issue that rests on her shoulders, "the pushing of ICT as much as possible ... giving tips to the staff-tools, shortcuts and the like ... enforces the issue in the school_receiving questions, being a model for using ICT whenever possible." From this one can say that implementing the issue of ICT is the coordinator's responsibility. There are coordinators who state that they are responsible for the entire process of implementing ICT in the school. For example: the Interviewee R states, general responsibility for equipment, pedagogical processes for improving teaching - learning and improving teaching quality, "Responsibility for proper management of the equipment and promotion of pedagogical processes, improving teaching quality of all the teachers and promotion of the school in the field of expertise in the 21st century". The details of the activity can be seen from the interviewee's statement, "Acquiring content providers, deciding on content providers, negotiating prices with content providers, deciding which digital books they learned/will learn this year, generating passwords for all the pupils and teachers of the school, sending memorandums about special days things like safe surfing week, a computer-related activity, an explanation of how the content providers operate, the feasibility of online tasks, and other things that fall on us during the year." From this statement one can say that the coordinators are responsible for both the technical and pedagogical aspect of ICT. The findings indicate that the ICT coordinators feel a great responsibility, they are aware of the importance of their role and that they are a pivotal figure for implementing ICT in the school. The tasks of the ICT coordinator include many fields, they are responsible for the budget framework, contacting external suppliers, advancing the teaching-learning process and encouraging school projects. ICT coordinators are the key figures in driving the process of implementing ICT and their perception of their role is what explains their method of activity.

\subsubsection{Challenges}

This category addresses the challenges the coordinators face. In the framework of their activity many challenges arise both technical and pedagogical. The interviewers brought up the lack of will and motivation for cooperation on the part of the teachers for integrating computers into their classroom. According to the interviewee, $\mathrm{N}$, “... in pedagogical matters ... every field coordinator decides for herself, I do not have anybody to share with, and then the work is mainly me and my computer ... There are a few teachers who really do not understand the matter, and simply confuse the issue with irrelevant questions (even when they receive an answer it does not help them). Another difficulty is with people who receive a task in order to check it off and leave". The interviewee R. states that she adopts a mediation method that supports the teacher and includes the teacher's difficulties, "you must support the teacher, to encourage her... if the teacher is frustrated she will throw the object away ... and today it is impossible, you must bring something to the pupils so it will not be boring." It can be understood from this that the teachers are pressured to deliver online lessons by the students as well, and they must be helped to cope with the difficulties and overcome them to achieve the goal — teaching via electronic media. Interviewee $\mathrm{N}$ adds the issue of professional isolation as a special challenge in the work of the ICT coordinator in relation to other coordinator positions, "... in the eyes of the pedagogues ... every coordinator in the field chooses for himself. I don't have many to share with and then my work is essentially me and my computer". It can be seen from this that ICT coordinators face a unique challenge of professional isolation.

The interviews with the ICT coordinators also show that the technical challenge they face by the lack of resources which makes their day-to-day work more difficult. The coordinators mentioned equipment shortages and technical support in real time. This was raised by the Interviewee $\mathrm{N}$ when discussing shortage of equipment, "our problem is that we don't have enough means. We have one classroom that is occupied all day to full capacity ... they don't know where to go, how to operate it, how to manage it. In a second everything has changed. If we had two more classrooms it would look different. And in the game-room, the first thing that Luba said was we will buy computers because this is now a part of the school's life." Her words indicate that the significant challenge for her is the lack of equipment which would increase the pupil's work online. In addition, the interviewee $\mathrm{H}$ indicated an additional difficulty, lack of time to prepare online lessons, "the lack of time-preparing a worthwhile online lesson because it takes a lot of time to locate the best materials, creating games and creativity. I wish I could build a stock of sites where one teacher's work could multiply itself and save others time." The interviewee R mentions also the lack of technician hours, "if my principal did not see the importance of the technician ... and we often received service privately. Our school is independently financed and often has the budget to allocate to computers to help us."

These findings indicate that the coordinators face various technical challenges: shortage of equipment, lack of technical support and a large amount of time needed to prepare the optimal online lessons, along with pedagogical challenges such as isolation, daily work with teachers who are against change and who have 
learning disabilities or lack of motivation or technical skills who resist the daily work.

\subsubsection{Flexible Time}

The reference to flexibility of time in interviews with coordinators is broad. Some of them refer to the length of time required to assimilate a process. Some of them relate to the time required for meeting with teachers, and some of them refer to the time needed to organize the daily schedule in order to cope properly with their heavy workload. The interviewee L explains that the job of the ICT coordinator is limitless and that this is derived from his method of operation, "The ICT coordinator is first and foremost a teacher who does not have special hours for the job he performs. The job is done by the way, during study hours, breaks, etc. Therefore during the break or during study hour you circulate among the teachers asking or enquiring and helping when needed ... and usually the coordinator works alone". From this one can say that the work of the coordinator is constant, with non-specified hours during the day. Like the interviewee R emphasized the coordinator is available during breaks and even during his lesson, "during the break always talking to the teachers about their difficulties with the web or updating the schedule or reports. He is always being called by the principal to help some pilot or program that comes from above." In addition, interviewee R talks about prearranged training sessions, "monthly sessions with teachers for instruction, weekly sessions with the teaching staff: from his comments one can say that scheduled hours provides stability and achieves the goals of the coordinator". The interviewee R emphasizes the benefits/non-benefits of the coordinator's work, "When I had 4 hours as a coordinator it was dedicated to the teachers, the students and the administration, the work was wonderful and pleasant and I saw changes ... the minute they took these hours away ... it's not easy, it's not the same job". From her words it can be understood that these hours were built into the system, their contribution was recognized and the entire system benefited from it.

But the interviewee $\mathrm{G}$ describes satisfaction from the hours in her school and sees success in the model they have adopted, "as an ICT coordinator I have one hour in every class from grade 1 to grade 6". From her words we see that there are certain hours reserved in the schedule.

From these findings it can be said that there are coordinators that describe their work has no fixed schedule whereas other coordinators comment that they do have fixed hours.

\subsection{Work Relations}

The interviews show that the coordinator of ICT in his work is responsible and involved with various people and with officials in and outside the school. Thus, the coordinators' relations with the supervisor, the principal and the teachers, on the one hand, and the coordinator's relationship with the students on the other.

\subsubsection{ICT Coordinator's Relations with Supervision}

It is evident from the coordinators' testimonies that the connection with the supervisor is important and useful as the interviewee H points out, "You have to talk to someone who understands in order to plan properly, to learn from mistakes, and it helps to air frustrations". From interviewee H's words one can say there exists a need for a connection with the supervision for the purpose of advice and planning.

The interviewee $\mathrm{R}$ details in which subjects the supervisors help her, “... I tell her my needs and she helps me to learn to apply, ah ... we create a long distance support for every problem, I can turn to her after the training sessions ... she helps me decide which content suppliers to use, digital issues if I don't understand them, she teachers and helps me build the program in the field of cyber security as well, always helps me build the school program, she always informs me of new innovations in the field of ICT, training programs, every problem we encounter she checks and helps us find the best ideal solution. I learn a lot from her". From R's words one can see that the close ties with the supervision and the constant support facilitates the coordinator's work by providing tools, refreshing ideas, updating, building programs and consulting with discretion.

\subsubsection{The ICT Coordinator's Relationship with the Principal}

From the interviewees it is evident that the ICT coordinators work in constant cooperation with the school principals and that they have acquired the trust of the principal in fulfilling their duties and receive full support from them. From their words, one can see that there are principals who participate continuously in the work of the coordinator. As the interviewee R comments "I get a lot of backup and support from the principal". Once can see from her words that there exists collaboration between her and the principal and full support from the principal. The interviewee $\mathrm{R}$ added and described the assistance of the principal with professional difficulties, "ah ... in choosing content, with all of the program suppliers and content the principal relied on me completely. She relied on my discretion, on my pedagogical ability, our ability, mine and the supervisor". The interviewees affirm the reciprocal relations between the principal and the ICT coordinator. Some of the coordinators speak of 
complete faith of the principal in their work. Like $\mathrm{N}$ pointed out "choosing content providers for example, she is not even involved. It is completely autonomous, independent from the first second to the last, all she says is 'Tell me, did you choose yet, it's almost July 15th'. I don't even have to ask her about money ... she doesn't ask me about anything. Only at the end did I come to her and tell her what we have and she said 'excellent'." From her words one can sense the full confidence that exists between the principals and the coordinators. The interviewee $\mathrm{R}$ adds to this the frequency of meetings with the principal, "weekly meetings with the principal and the ICT coordinator ... I'm always being called to help with some pilot or project that comes from above". The frequency and character of the meetings affirms the importance that the principal attributes to this subject. From the findings one can say most of the coordinators feel that they have a successful and firm relationship with the principal and feel the trust the principal has in them, and the professional cooperation which is based on their confidence in the coordinator. It is also evident that the principals attach great importance to the issue of ICT.

\subsubsection{The ICT Coordinator's Relationship with the Teachers}

The relationship of the ICT coordinators with the teachers is expressed in various ways: in teaching the teachers, in the pedagogical and technical aspects; the schedules and technical and pedagogical challenges. The work of the coordinator is expressed in the introduction of content related to the learning program as interviewee $\mathrm{L}$ states "I sit with a teacher, staff and introduce them to content-I give them the feeling that they are deciding what is best for their class, I tempt them with new tools," From this one can see how the coordinators reveals to the teachers new tools for integrating the computer into teaching. The interviewee R says she uses the fan method, "the instructor and I ... helped the teachers ... to show them the added value of ICT in the lesson". Not only introducing content but also emphasizing the added value combining ICT with teaching. The interviewee A relates the process that was built in accordance of the needs that arise in the school as a result of organized mapping, the coordinator chooses the teachers who will work with them, "I map out the staff according to areas of expertise, computer skills, and personality of the teachers and I choose the teachers who will help me lead the projects. On the other hand, I take teachers who are having difficulties and try to advance them in their work. I work in tandem with the administration and together we create a climate that advances the learning by integrating ICT'. From this one can see that the coordinator is the initiator in choosing teachers and types of projects in order to advance the learning combined with ICT. In addition, the coordinator chooses the teachers who are having difficulty in integrating ICT with their work.

From the comments of the interviewees it is clear that instructing the teachers is the main pedagogic work of the ICT coordinator. The interviewee E explains, "the ICT pedagogic coordinator... most of the work is in instruction. Some of it is in guidance". The interviewee L describes how and in which areas the guidance is conducted. "Helping the teachers and principal in assimilating the program and making the program practical, and applicable while adapting it for the school and the teacher. Passwords for the pupils, maintaining the site, preparing for emergencies, and accessing sites for the teachers including IMS which helps the teachers overcome the hurdles of the computer, facilitates pedagogical teaching with the computer, takes care of the printer network". From his comments one can say that the coordinator is involved in many subjects while training the teachers, from pedagogy to ICT integration to assisting in technical issues. The coordinator's activities are divided between the pedagogical and technical aspects which are intertwined with each other and attest to each other's existence. Thus the technical indicators testify to their pedagogical uses and the training instruction is essentially giving a technical solution that allows pedagogy.

\subsubsection{The ICT Coordinators Relationship with the Pupils}

From the statements of the coordinators on their relationship with the pupils in the school it appears that there is a connection between the coordinators and the pupils. The interviewee $\mathrm{R}$ recounts his weekly meeting with a committee of pupils which was created to advance this subject, "a weekly session with the computer committee", the committee includes pupils. And R also relates that his work with the pupils including the Amirim group lead to computerizing advances and this group even helped the teachers. "We led the Amirim group, a group of pupils that learned ICT. And every pupil in the school wanted to integrate ... very much. And we had a group that helped the teachers who had received training, and every group belonged to a site, to their own class portal, and they maintained it". From these quotes it can be deduced that the ICT coordinator created a committee of pupils who are leaders and help the teachers and coordinator to integrate computers into the learning. It is evident that the ICT coordinators are in constant contact with the committee of pupils who are the leaders in the school. A relationship makes a significant contribution to the atmosphere of the school and advances the teaching-learning process in general in the school. 


\section{Discussion}

This study examined the work of the ICT coordinators in the school in light of the ICT program of adapting the education system to the 21 st century, for the unique point of view of the ICT coordinators. The findings of the study point to three main categories: the perceptions of the coordinator, the characteristics of the job, and the work relations.

\subsection{The Perceptions of the Coordinator}

The coordinators perceive their job as facilitators, leading and encouraging the implementation of ICT in the school. The coordinators have a vision and clear goals, which characteristics enable them to advance their goals that they have set for themselves and encourages the feelings of the coordinators that their job is essential to the management of the organization and that it cannot survive without them (Gross-Bruner, 2003; Scheinfeld \& Zelkovitz, 2010). In addition, one can identify their emotional commitment to the job, and the tasks that result from it to an organization which is compatible with studies dealing with the behavior patterns of teachers who consider themselves committed to the job and the school and cause effective implementation and significant change (Avidav-Ungar \& Iluz, 2013). The coordinators assume their roles with a clear understanding that ICT in the school is not about using the computer but rather a combination of possibilities embodied in the technological media and applying the tools in an intelligent manner. Similar ideas were found in the policy documents of the Ministry of Education (Ministry of Education, 2012). The optimal implementation of ICT in school according the coordinators, will occur when the teachers discover independence in creating content, they will use discretion in choosing exact tools that are suitable for their needs, will succeed in broadening the boundaries of learning beyond the walls of the classroom and will share with their pupils both the choice of content and the building of learning and the creation of significant products in accordance with the goals defined by the ICT program (Rimon, 2012).

\subsection{Characteristics of the Job}

The areas of responsibility of the ICT coordinator are numerous and encompass many fields, from fulfilling day to day tasks of the ICT coordinator in the school to overseeing the technical equipment to responsibility for the training programs. The coordinators are responsible for the budget framework, they are contact with outside suppliers, advancing teacher-learning programs and leading school projects (Ministry of Education, 2016; Devolder et al., 2010). ICT coordinators are key figures in moving the process of ICT implementation forward and their perception of their job explains their mode of operation. In accordance with the Scheinfeld and Zelkowitz's study (2010), which explains that ICT implementation includes a comprehensive change in the school which means implementation of learning programs and changing the organizational culture of the institution. This change can be accomplished by the leadership of the ICT coordinator who combines in a practical manner the three main roles of his job: ICT expert, teacher and ICT instructor and a leader for change so that all three complement each other. In addition, the study found that the instruction activities are divided between the pedagogical and the technical aspects which are combined together. They express themselves in the pedagogical aspect of introducing content that is connected to the learning process and by introducing new tools that combine the computer and teaching (Rotem \& Avni, 2012; Schwartz et al., 2014). The technical challenges faced by the coordinators like lack of resources weigh heavily on their day-to-day work due to the lack of equipment, the technical support and the time required for effective implementation of teacher training, and the lack of time that is needed to prepare a worthwhile online lesson. Digital content which is not appropriate to the learning program is useless to the professional development of the teachers who must learn to exploit the advantages of the ICT (Ministry of Education, 2012). In addition, appropriate teaching and training will be provided to computer coordinators which will maximize their personal and professional potential for improving their work (Adey, 2000), which is required to prepare a valuable online lesson. After analyzing the comments of the ICT coordinators the research found a broad reference to time flexibility. Some of them refer to the length of time required to assimilate a process. As many studies have shown that successful assimilation in organizational culture (Avidav-Ungar, 2010) is a process of a decade rather than a few years (Salant, 1992).

\subsection{Work Relationships}

From the testimony of the coordinators it is evident that their connection with the instructors and supervisors contributes a great deal to them, discerning and focusing their judgment, exchanging of views, and the learning possibilities that are open to them in this communication channel. The coordinators benefit from the guidance and supervision they receive from their peers, examining initiatives, using additional considerations and learning new content and tools. Regarding the connection between ICT coordinators and the school administration it was found that they work in constant partnership and they have acquired the trust of the principal in fulfilling their 
role and receiving their full support. One can also see that there are principals who participate constantly with the coordinators. In addition, the coordinators testify that in most instances they feel a good and firm connection with the principal which sits well with the rational of the coordinators role as a right hand man of the principal with all that is connected to ICT implementation in the school, and he will execute some of the directives in cooperation with the school principal, and some he will execute on his own and take the lead for it is up to him to help and advise the school principal on the ICT implementation in the school. This finding agrees with the findings of the research done by Bass (1985) which examined the influence of a leader on his workers. Among the findings from his research it seems the workers testified their willingness to meet the expectations of the leader and there developed an emotional commitment to the organization and the task. They described a leader who demanded high standards of performance and supported his men emotionally with advice and an ability to appreciate their efforts and achievements, and speak openly. They felt a sense of security along with the knowledge that the leader was really attuned to them and this gave them a great deal of autonomy and encouraged their personal development. Regarding the connection between the coordinators and the teachers, it was found that the coordinator shows the teachers that technology can support pedagogy and can be part of the learning-teaching-evaluation process (Rodriguez-Miranda et al., 2014). These findings support the findings of Eyal's (2016) research that the role of the coordinator is not just pedagogic instruction but also system-wise and deals with leading change not as individuals but rather to establish a teacher leadership that cooperates in advancing the school. The coordinators have a strong connection with the pupils who belong to the leadership groups in the school. These connections contribute greatly to the school atmosphere and advance the whole teaching-learning process in the school, where the ultimate goal is introducing ICT which will advance the process of building a meaningful learning process for the pupils of the school. It has been found that ICT has contributed greatly as a means of generating interest, increasing motivation and empowering students' abilities (Avidav-Unger \& Shamir-Inbal, 2013).

\section{Limitations of the Study}

The study was conducted using a qualitative approach that by its very nature delves into the subjective experience. Therefore, the validity of the research is limited to a large extent and cannot be generalized to the general population. Of course, more interviews in general would have enabled a broader perspective on the work of the ICT coordinator.

\section{References}

Adey, K. (2000). Professional Development Priorities: The Views of Middle Managers in Secondary Schools. Educational Management Administration \& Leadership, 28(4), 419-431. https://doi.org/10.1177/0263211X000284005

Attride-Stirling, J. (2001). Thematic Networks: An Analytic Tool for Qualitative Research. Qualitative Research, l(3), 385-405. https://doi.org/10.1177/146879410100100307

Avidav-Ungar, O. (2010). "Islands of Innovation" or "Comprehensive Innovation" Assimilating Educational Technology in Teaching, Learning, and Management: A Case Study of School Networks in Israel. Interdisciplinary Journal of E-Learning and Learning, 6, 259-280. https://doi.org/10.28945/1314

Avidav-Unger, A., \& Eshet-Alkalai, Y. (2012). Implementing the Technological Innovations in the Education System: Models and Goals. Model "The Island of Suspicion" for the Effective Implementation of the Technological Innovations in the Education System: Analyzing the Main Reasons for Failure of the Model. Gadish: Journal of Adult Education, 13, 43-61.

Avidav-Unger, O., \& Vailuz, A. (2013). Empowerment Creates Changes among Teachers Leading the ICT in Education. In Y. Eshet-Alkalai, A. Caspi, S. Eden, N. Gary, Y. Kelman, \& Y. Yair (Eds.), Chase Conference for Research in Learning Technologies 2013: The Man Who Learns in the Technological Era (pp. 1-9). Ra'anana: The Open University.

Avidov-Ungar, O., \& Shamir-Inbal, T. (2013). Empowerment Patterns of Leaders in ICT and School Strengths Following the Implementation of National ICT Reform. Journal of Information Technology Education, 12, 141-158. https://doi.org/10.28945/1865

Bass, B. M. (1985). Leadership and performance beyond expectations. New York: Free Press.

Braun, V., \& Clarke, V. (2006). Using Thematic Analysis in Psychology. Qualitative Research in Psychology, 3(2), 77-101. https://doi.org/10.1191/1478088706qp063oa

Darling-Hammond, L., \& Bransford, J. (2005). Preparing Teachers for a Changing World: What Teachers Should Learn and be Able to Do. San Francisco: John Wiley. 
Devolder, A., Vanderlinde, R., Braak, J., \& Tondeur, J. (2010). Identifying multiple roles of ICT coordinators. Computers \& Education, 55(4), 1651-1655. https://doi.org/10.1016/j.compedu.2010.07.007

Ellis, H., Havard, B., Hastings, N., \& McArthur, A. (2016). Educational Leaders As Technology Leaders: Technology Literacy Skill Development. In G. Chamblee, \& L. Langub (Eds.), Proceedings of Society for Information Technology \& Teacher Education International Conference (pp. 1217-1223). Savannah, GA, United States: Association for the Advancement of Computing in Education (AACE). Retrieved from https://www.learntechlib.org/p/171843

Eyal, L. (2016). from the laboratory to the field - Plan of action for Teachers and ICT Leaders (Poster). The 14th MEITAL Conference.

Gross-Brenner, A. (2003). A Description of the ICT Coordinator's Job in the School. Retrieved March 8, 2017, from http://www.leadersnet.co.il

Kleiman, S., \& Zamir, A. (2008). Computer Technician or Agent for Change? - How is the ICT Coordinators Job Perceived in the School? Oranim Academic College of Education, Research and Evaluation Authority. Retrieved August 8, 2017, from https://goo.gl/PLz7Ao

Kozma, R. B. (2003). Technology and Classroom Practices: An International Study. Journal of Research on Technology in Education, 36(1), 1-14. https://doi.org/10.1080/15391523.2003.10782399

Melamed, O. (2000). Report of the Committee for the Definition of ICT Policy in the Education System. Jerusalem, Israel: Ministry of Education.

Ministry of Education Technology, IT and Information Technology Department. (2016). Defining the Role of A School Coordinator. Retrieved from the educational cloud: All the e-services for the schools http://sites.education.gov.il/cloud/home/tikshuv/Pages/hanhaiot_le_baaley_tafkidim_ve_rakazim.aspx

Ministry of Education. (2012). Adapting the education system to the 21st century. Israel: Jerusalem.

Ministry of Education. (2016). ITC program officers. Retrieved from the educational cloud: http://sites.education.gov.il/cloud/home/tikshuv/Pages/bahaly_tafkidim_ticshuv.aspx

Mishra, P., \& Koehler, M. J. (2006). Technological Pedagogical Content Knowledge: A Framework for Teacher $\begin{array}{lllll}\text { Knowledge. Teachers } & \text { College } & \text { Record, } & \text { 108(6), } & \text { 1017-1054. }\end{array}$ https://doi.org/10.1111/j.1467-9620.2006.00684.x

Rimon, A. (2012). The National Program Adapting the Education System to the 21st Century (Position Paper). $54,284-292$.

Rotem, A., \& Avni, I. (2012). The Pendulum of Educational Activity: from Technophobia to Technomania, and back to TechnoMedia, but What about Pedagogy? Ethical Ethics.

Salant, A. (1992). Educational Reform: The Time Factor. In A. Salant, \& T. Greenberg (Eds.), A Window to Educational Systems around the World, 10, 17-18.

Scheinfeld, M., \& Zilkowitz, T. (2010). Behind the Scenes: Characteristics of ICT coordinator's work. Education and its Surroundings, 32, 61-78.

Schwartz, T., Avidav-Unger, A., \& Eshet-Alkalai Y. (2014). Gaps in the Perception of Learning Technologies as an Obstacle in Effective Assimilation: The Case of Assimilation of Smart Boards in the Education System. In Y. Yair \& A. Shmueli (Eds.), Meital Twelfth Conference (pp. 461-467). Tel Aviv: Meital.

Tobin, D., \& Dayan, A. (2007). Establishing a new role in the school: the case of the ICT coordinator. Studies in the Administration and Education Organization, 29, 89-106.

Ungar, O., \& Shamir-Inbal, T. (2016). ICT Coordinators 42019 TPACK-based Leadership Knowledge in their Roles as Agents of Change. Journal of Information Technology Education: Research, 16(1), 169-188. Retrieved from https://www.learntechlib.org/p/181046

Vaillant, D. (2005). Education reform and the role of teachers. In Prelac Journal. Teacher involvement in educational change. Santiago, Chile: UNESCO.

\section{Copyrights}

Copyright for this article is retained by the author(s), with first publication rights granted to the journal.

This is an open-access article distributed under the terms and conditions of the Creative Commons Attribution license (http://creativecommons.org/licenses/by/4.0/). 